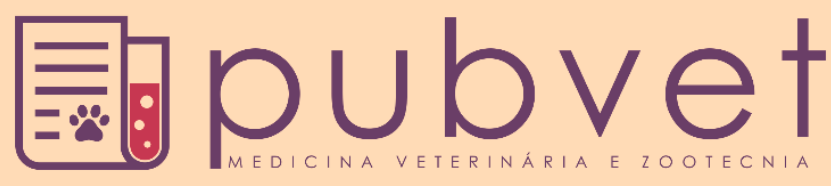

https://doi.org/10.31533/pubvet.v14n2a502.1-11

\title{
A compostagem de carcaças de animais mortos elimina microrganismos patogênicos
}

\author{
Leandro Serrano ${ }^{1}$, Vanessa Romário de Paula ${ }^{2} \theta$, João Batista Ribeiro ${ }^{3}{ }^{\oplus}$, Márcio Roberto \\ Silva $^{3 \bullet}$, Célio de Freitas ${ }^{2}{ }^{\circ}$, Marcelo Henrique Otenio ${ }^{3 *} \bullet$ \\ ${ }^{1}$ Mestre em Ciência e Tecnologia de Leite pela Universidade Federal de Juiz de Fora. Juiz de Fora -MG, Brasil. \\ ${ }^{2}$ Analista da Empresa Brasileira de Pesquisa Agropecuária Juiz de Fora-MG, Brasil. \\ ${ }^{3}$ Pesquisador da Empresa Brasileira de Pesquisa Agropecuária Juiz de Fora-MG, Brasil. \\ *Autor para correspondência, E-mail: marcelo.otenio@embrapa.br
}

Resumo. O descarte de carcaças de bovinos representa um potencial passivo econômico e ambiental. A destinação de carcaças de bovinos é um ponto crítico nas propriedades rurais, em que a mortalidade de animais é uma realidade, somado às dificuldades para seu descarte adequado. A destinação de carcaças de forma inadequada favorece a contaminação ambiental por microrganismos patogênicos, colocando em risco a saúde humana e animal e o meio ambiente. A compostagem é um processo biológico de decomposição da matéria orgânica e uma alternativa prática e simples para destinação de carcaça. Este trabalho avaliou o efeito da compostagem sobre a viabilidade de microrganismos indicadores, e relevantes para a bovinocultura. Esferas plásticas contendo microrganismos patogênicos liofilizados Echerichia coli, Enterococcus faecalis, Pseudomonas aeruginosa, Listeria monocytogenes, Streptococcus uberis, Staphylococcus aureus, Bacillus cereus e Salmonella Typhimurium, foram colocadas em pontos estratégicos no interior da carcaça dos animais e na leira de compostagem, com o objetivo de monitorar a presença destes microrganismos durante o processo. As esferas foram retiradas das leiras de compostagem após 7, 15, 30, 60 e 90 dias para análises microbiológicas. Os resultados mostraram que a compostagem reduz e/ou elimina microrganismos patogênicos. A compostagem oferece segurança microbiológica para o uso do bio-composto gerado como fertilizante.

Palavras chave: Bactérias patogênicas, descarte, mortalidade animal, processo aeróbio

\section{Composting carcasses of dead animals eliminates pathogenic microorganisms}

Abstract. The disposal of cattle carcasses is a potential economic and environmental liability. The destination of cattle carcasses is a critical point in rural properties, where animal mortality is a reality, added to the difficulties for its proper disposal. Inappropriate disposal of carcasses brings environmental contamination by pathogenic microorganisms, endangering human and animal health and the environment. Composting is a biological decomposition process of organic matter and a practical and simple alternative for carcass disposal. Was evaluated the effect of composting on the viability of indicator microorganisms relevant to cattle breeding. Plastic spheres containing lyophilized pathogenic microorganisms Echerichia coli, Enterococcus faecalis, Pseudomonas aeruginosa, Listeria monocytogenes, Streptococcus uberis, Staphylococcus aureus, Bacillus cereus and Salmonella Typhimurium, were placed at strategic points inside the carcass and in the compost piles, to monitor the presence of these microorganisms during the process. Plastic balls were removed from composting piles 7, 15, 30, 60 and 90 days for microbiological analysis. The results showed that composting reduces and / or 
eliminates pathogenic microorganisms. Composting provides microbiological safety for the use of the bio-compost generated as fertilizer.

Keywords: Aerobic process, animal mortality, disposal, pathogenic bacteria

\section{El compostaje de las canales de animales muertos elimina los microorganismos patógenos}

Resumen. La eliminación de cadáveres de ganado representa una posible responsabilidad económica y ambiental. El destino de las canales de ganado es un punto crítico en las propiedades rurales, donde la mortalidad animal es una realidad, sumado a las dificultades para su eliminación adecuada. La eliminación inadecuada de las canales favorece la contaminación ambiental por microorganismos patógenos, poniendo en peligro la salud humana y animal y el medio ambiente. El compostaje es un proceso de descomposición biológica de materia orgánica y una alternativa práctica y simple para la eliminación de las canales. Este trabajo evaluó el efecto del compostaje en la viabilidad de microorganismos indicadores relevantes para la cría de ganado. Esferas de plástico que contienen microorganismos patógenos liofilizados Echerichia coli, Enterococcus faecalis, Pseudomonas aeruginosa, Listeria monocytogenes, Streptococcus uberis, Staphylococcus aureus, Bacillus cereus y Salmonella Typhimurium, se colocaron en puntos estratégicos dentro de la carcasa del animal y en el pila de compostaje, para monitorear la presencia de estos microorganismos durante el proceso. Las esferas se retiraron de la pila de compostaje después de 7, 15, 30, 60 y 90 días para el análisis microbiológico. Los resultados mostraron que el compostaje reduce y / o elimina los microorganismos patógenos. El compostaje proporciona seguridad microbiológica para el uso del compuesto generado como fertilizante.

Palabras clave: Bacterias patógenas, descarte, mortalidad animal, proceso aeróbico

\section{Introdução}

A bovinocultura é atividade econômica de destaque no agronegócio (Prado, 2010). O rebanho brasileiro está distribuído em aproximadamente 180 milhões de hectares e atinge 214,9 milhões de cabeças (ANUALPEC, 2019; Ferraz \& Felício, 2010). A preocupação ambiental tem se tornado efetiva, pois, qualquer que seja o resíduo gerado, se não houver um tratamento adequado, pode acarretar fatores adversos ao meio ambiente e concomitantemente aos seres humanos (Rocha, 2012). Um índice considerado normal de mortalidade é de 3 a $5 \%$ do rebanho ao ano, o que corresponde a uma quantidade significativa de carcaças de bovinos mortos (Paula et al., 2017). O aumento da consciência ambiental e da vigilância de órgãos fiscalizadores tem induzido a busca para uma destinação mais adequada das carcaças de animais. Uma alternativa para destinação dessas carcaças é a compostagem, um processo biológico de decomposição da matéria orgânica realizado pelos microrganismos que reciclam resíduos de origem orgânica. Segundo Otenio et al. (2010), a compostagem, além de não causar poluição no solo ou na água, destrói os microrganismos patogênicos, pode ser feita em qualquer época do ano e gera um bio-composto que pode ser aplicado no solo.

Gerenciar os resíduos orgânicos de forma adequada traz benefícios relacionados à prevenção da poluição de cursos d'água e do solo, diminuindo o risco de disseminação de doença, produzindo adubos orgânicos para uso agrícola. A compostagem se constitui em técnica importante para o tratamento dos resíduos gerados no meio rural, apesar de pouco difundida entre agricultores no Brasil, a não ser entre agricultores orgânicos (Miller \& Inácio, 2009).

A definição de compostagem pode variar conforme o enfoque microbiológico, agronômico ou ambiental. Mas todas ressaltam o caráter aeróbico e termofílico. Sendo assim, a compostagem é um processo da biodecomposição da matéria orgânica dependente de oxigênio e com geração de calor, à temperaturas típicas de $50^{\circ} \mathrm{C}$ a $65^{\circ} \mathrm{C}$ e picos que podem chegar a mais de $70^{\circ} \mathrm{C}$ (Miller \& Inácio, 2009). Para que a compostagem ocorra deve haver uma razão de C:N próximo a 15 (Brinton et al., 2012).

Outros processos de descarte de carcaças de animais mortos por motivos naturais, patológicos, acidentes ou por fenômenos da natureza (raios ou mudanças climáticas repentinas) podem ser adotadas como, por 
exemplo, a incineração. Entretanto, os altos custos de incineração inviabilizam essa alternativa de destinação de carcaças (Kalbasi et al., 2005; Krabbe, 2017). O enterro dos animais mortos é uma prática comum para o descarte das carcaças, embora cause impactos ambientais indesejáveis e riscos de disseminação de doenças.

A compostagem é uma opção viável, pois não onera os custos da propriedade rural e é fácil, rápido e prática de se realizar (Diniz Filho et al., 2007; Kiehl, 2004; Sanes et al., 2015). A matéria prima utilizada na compostagem é encontrada na propriedade rural, como a sobra da alimentação do gado (volumoso), restos de silagem, esterco seco, aparas de capim e serragem. No processo de compostagem ocorre uma interação da microbiota presente no animal e do material vegetal.

Este estudo avaliou a eficiência do processo de compostagem quanto à redução e ou eliminação de microrganismos patogênicos, inoculados no processo de compostagem.

\section{Material e métodos}

O experimento foi realizado no campo experimental da Embrapa Gado de Leite, localizado no

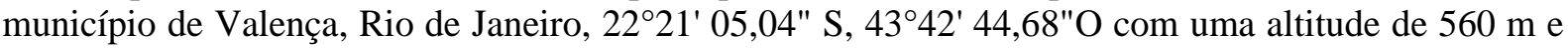
clima apresentando uma estação com precipitação e quente e uma estação seca e com temperaturas amenas (Köppen \& Geiger, 1928).

O estudo utilizou o delineamento em bloco ao acaso, onde foi planejado em condições homogêneas e com repetições dos tratamentos, casualizados e controladas em todas as etapas da pesquisa.

\section{Delineamento experimental}

As pilhas de compostagem foram montadas, em maio e acompanhadas nos meses de maio, junho, julho e agosto (estação seca) no ano de 2017. E em 2017 e 2018, montadas no mês de novembro e acompanhadas em novembro, dezembro, janeiro e fevereiro (estação chuvosa). Foram montadas cinco leiras de compostagem, cada uma delas contendo uma carcaça bovina. As carcaças eram de bovinos fêmeas com peso médio de $450 \mathrm{~kg}$ da raça Girolanda, com critérios de não estarem doentes, não terem sido tratadas com antibiótico terapia nos últimos seis meses. Os animais foram eutanasiados. A realização do experimento seguiu as diretrizes do Comitê de Ética para Uso de Animais - CEUA da Embrapa Gado de Leite e tem o protocolo de autorização: 1762160316. As leiras foram montadas de forma uniforme, com o mesmo material vegetal picado (bambu triturado/previamente seco a sombra, em partículas de no máximo dois $\mathrm{cm}$ ), mesmas condições físicas de estrutura.

Em cada carcaça, foram introduzidas seis esferas plásticas em pontos pré-definidos, como na base interna da compostagem, no interior da carcaça do animal (boca, rúmen, pele, úbere) e na parte superior interna da compostagem.

As esferas continham os seguintes microrganismos, Echerichia coli, Enterococcus faecalis, Pseudomonas aeruginosa, Listeria monocytogenes, Streptococcus uberis, Staphylococcus aureus, Bacillus cereus e Salmonella typhimurium. O preparo dos inóculos foi realizado nos laboratórios de microbiologia da Embrapa Gado de Leite. Os microrganismos foram cultivados, liofilizados e colocados em envelopes de nylon contendo material vegetal moído e estéril (bambu). Os envelopes de nylon foram acondicionados em esferas plásticas (Figura 1), resistentes a altas temperaturas e pressão, de $75 \mathrm{~mm}$ de diâmetro, parede de 1,5 mm e perfuradas com abertura de dois $\mathrm{mm}$.

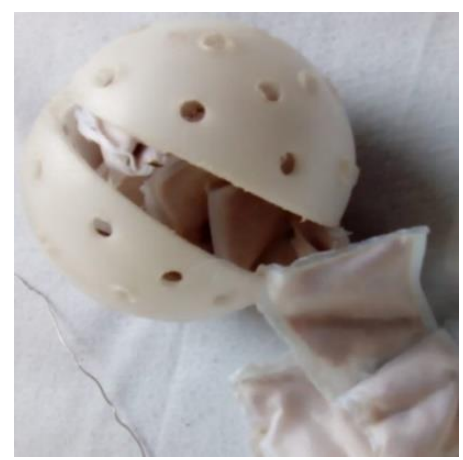

Figura 1. Esferas plásticas

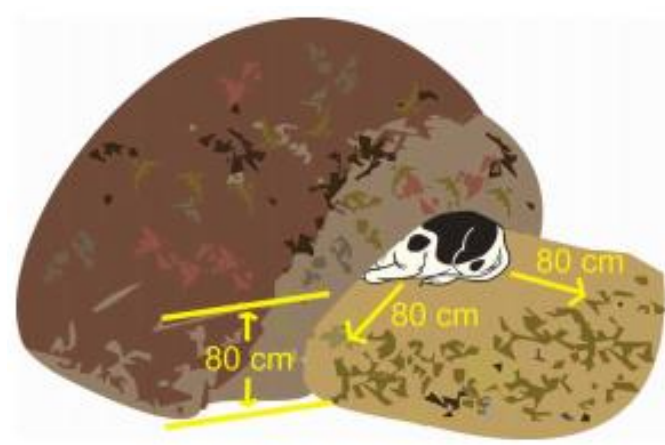

Figura 2. Disposição dos animais nas leiras 
A compostagem foi realizada em local descoberto, com piso plano e impermeável, distante de fontes naturais de águas, de fácil acesso a carga e descarga do material utilizado e cercado com cerca elétrica. As leiras foram montadas com material vegetal seco (bambu triturado) formando uma base de $80 \mathrm{~cm}$ de altura, 2,5 metros de largura e 4 metros de comprimento. As cinco leiras foram montadas em sequência e as carcaças foram posicionadas uniformemente (Figura 2). O rúmen dos bovinos foi perfurado para se evitar a explosão pela fermentação no interior. As carcaças foram cobertas com o mesmo material vegetal usado na base. A leira de compostagem atingiu aproximadamente 1,70 metros de altura. Ao redor das leiras de compostagem, foi feito uma proteção com cerca elétrica, para impedir o acesso de animais domésticos e silvestres às carcaças dos animais no interior da compostagem (Figura 3).

$\mathrm{O}$ experimento foi realizado em dois períodos. O primeiro no inverno, compreendendo os meses de maio, junho, julho e agosto e outro no verão, entre os meses novembro, dezembro, janeiro e fevereiro.Foram monitorados diariamente os parâmetros de temperatura no interior da compostagem, as condições ambientais (chuva, temperatura e umidade) e o aparecimento de chorume.

A temperatura no interior da compostagem foi monitorada durante os 90 dias com leituras diárias, utilizando termômetro de digital (TH-200), introduzido no interior da compostagem com auxílio de um tubo de ferro galvanizado (Figura 4).

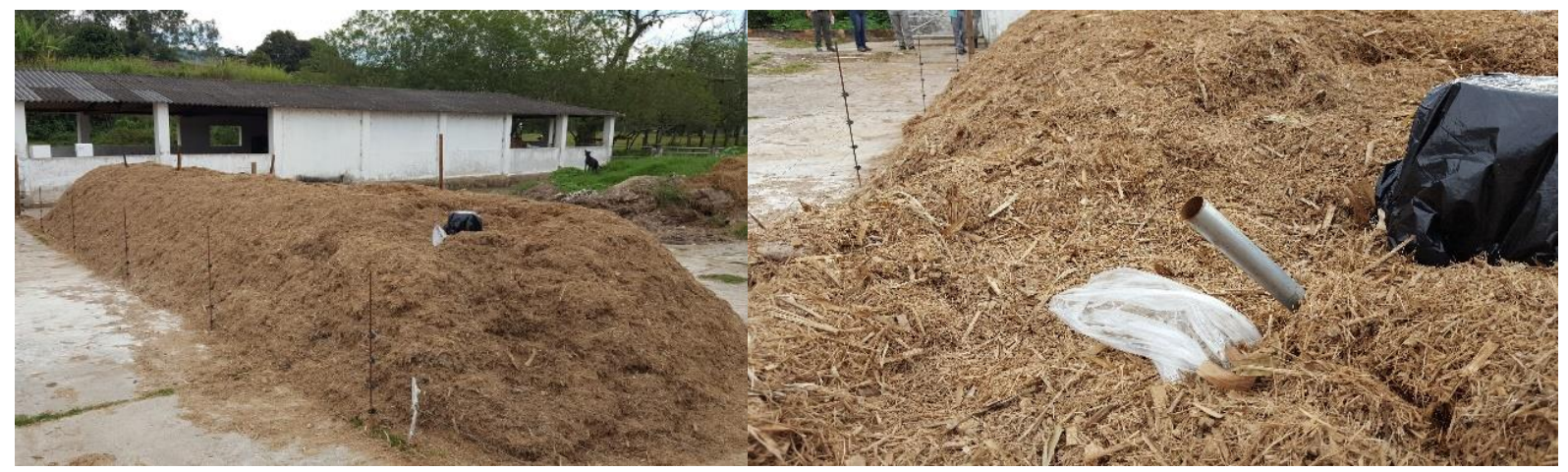

Figura 3. Cerca elétrica ao redor da leira.

Figura 4. Tubo de medição de temperatura no interior da pilha

As esferas foram retiradas das leiras de compostagem após 7, 15, 30, 60 e 90 dias para análises microbiológicas. Cada leira contendo um animal correspondia a um período de compostagem e tempo de coleta. As esferas foram retiradas, envolvidas em papel filme e acondicionadas e refrigeradas em caixas térmicas para transporte até o laboratório de microbiologia. Além das esferas, foi recolhida uma amostra do material no entorno das esferas, num raio de $30 \mathrm{~cm}$.

As amostras biológicas coletadas na compostagem para análise foram: o material vegetal do interior da esfera plástica, os envelopes contendo os microrganismos liofilizados; amostras coletadas ao redor da esfera. Além das coletas das esferas, foi coletado material em torno dos seis pontos onde foram posicionadas as esferas, sendo eles: boca, rúmen, úbere, pele, cama (embaixo do animal) e superfície (por cima do animal) para análise de umidade e $\mathrm{pH}$.

\section{Metodologia de microbiologia qualitativa}

As análises microbiológicas foram realizadas com objetivo de identificar a presença ou ausência dos microrganismos na compostagem. As análises foram realizadas conforme critérios da Agência Nacional de Vigilância Sanitária (2013).

Todas as amostras foram ativadas em água peptonada $10 \%$, além de alguns casos específicos com meio de enriquecimento diferenciado. Para análise de Escherichia coli foi utilizado o meio de enriquecimento Caldo Rappaport e meio Ágar EMB, e foi identificada como fermentadora de lactose apresentando coloração verde metálico. Enterococcus faecalis, foi analisada em meio ágar Triple Sugar Iron e identificada apresentando colônias amarelas pequenas. Pseudomonas aeruginosa foi analisada em meio ágar MacConkey e identificada apresentando colônias bege ou incolor, meio amarelo/ âmbar. Listeria monocytogenes foi analisada em meio ágar Brillance Listeria e identificada apresentando colônias cinza esverdeadas. Streptococcus uberis foi analisada em meio ágar sangue, identificada 
apresentando colônias com hemólise beta. Staphylococcus aureus foi analisada em meio ágar Manitol e identificada apresentando colônias que alteravam o meio de cultivo para amarelo (fermentação de dmanitol). O Bacillus cereus analisada em meio ágar Manitol, com adição de gema de ovo piruvato, e identificada como colônias apresentando colônias de coloração azul. A Salmonella typhimurium foi ativado a partir do meio de enriquecimento em Caldo Selenito Cistina analisada em meio ágar SS e identificada apresentando colônias de coloração bege com centro negro. Os resultados foram expressos em presença ou ausência.

\section{Identificação dos microrganismos por testes bioquímicos}

A partir de colônias típicas isoladas nos meios seletivos, foi feita semeadura em meio BHI (Brain Heart Infusion Agar) e incubação à $35^{\circ} \mathrm{C} / 24 \mathrm{hs}$.

A identificação morfológica foi realizada com a coloração de Gram, as bactérias cocos Gram positivos estafilococos, enterococos, estreptococos e listerias; e as bactérias, bacilos Gram negativos enterobactérias, salmonelas, pseudomonas.

O Ágar SIM foi utilizado para a diferenciação de microrganismos com base na produção de sulfeto de hidrogênio, indol e motilidade. O teste de Indol é positivo para Escherichia coli, a produção de $\mathrm{H} 2 \mathrm{~S}$ é positiva para Salmonella typhimurium, e a motilidade bacteriana é identificada nos microrganismos Escherichia coli, Salmonella typhimurium, Pseudomonas aeruginosa e Bacillus cereus.

$\mathrm{O}$ teste de catalase foi realizado para detectar a presença da enzima catalase nos microrganismos. Os resultados são positivos para Escherichia coli, Salmonella typhimurium, Pseudomonas aeruginosa, Listeria monocytogenes, Staphylococcus aureus e Bacillus cereus. O teste de oxidase foi realizado para determinar a presença ou ausência de atividade de oxidase em bactérias. Os resultados são positivos para Pseudomonas aeruginosa, diferenciando estas da Escherichia coli que é oxidase negativa. A prova de Bile-Esculina é baseada na capacidade de algumas bactérias hidrolisarem esculina em presença de bílis, que consiste na prova diferencial positiva para Enterococcus faecalis e para Streptococcus uberis. O teste com o meio MR - VP (Methyl Red, Voges Proskauer) é baseado na capacidade dos microrganismos para oxidar a glicose com produção e manutenção de concentrações altas de produtos ácidos, considerado assim um teste confirmativo para Escherichia coli (MR, positivo e VP, negativo). Teste de coagulase foi utilizado para confirmação da espécie Staphylococcus aureus, coagulase positivo.

\section{Resultados e discussão}

\section{Parâmetros físico-químicos}

Os parâmetros físico-químicos são usados como indicadores da eficácia do processo de compostagem (Santos Nascimento et al., 2018). Os fatores físico-químicos monitorados nesse estudo têm influência direta na decomposição da matéria orgânica. Segundo (Cooper et al., 2010) quando a matéria orgânica é decomposta o calor criado pelo metabolismo dos microrganismos se dissipa. Na compostagem de resíduos orgânicos, em condições controladas, o calor gerado acumula no interior das leiras e a temperatura interna alcança valores elevados.

A temperatura é um fator determinante no processo de biodegradação da matéria orgânica e à eliminação dos possíveis patógenos presentes (Gardoni \& Azevedo, 2019). Ressalta-se que a manutenção da temperatura elevada $\left(50^{\circ} \mathrm{C} \mathrm{e} 75^{\circ} \mathrm{C}\right)$ no início do processo, bem como com um tempo de exposição suficiente, é fundamental para a eliminação de alguns microrganismos (Valente et al., 2009). A temperatura varia durante o processo de compostagem. Nas temperaturas superiores a $40^{\circ} \mathrm{C}$ predominam os microrganismos termofílicos, responsáveis pela decomposição acelerada da matéria orgânica.

A figura 5 (a) mostra que no período de seca as temperaturas alcançam $60^{\circ} \mathrm{C}$ no interior das leiras na primeira semana (7 dias) e mantêm-se por 30 dias. No período de chuva (b) as temperaturas alcançam $60^{\circ} \mathrm{C}$ na primeira semana e $70^{\circ} \mathrm{C} \mathrm{em} 14$ dias. Entre o $7^{\circ}$ dia e o $60^{\circ}$ dia de compostagem as temperaturas mantiveram-se acima de $40^{\circ} \mathrm{C}$. A partir de $60^{\circ}$ dia de compostagem a temperatura no interior da leira foi reduzindo, ficando abaixo de $40^{\circ} \mathrm{C}$. Segundo (Xu et al., 2014) a compostagem é dividida em estágios mesofílicos, em que as temperaturas estão abaixo de $40^{\circ} \mathrm{C}$ e termofílicos quando as temperaturas estão 
acima de $40^{\circ} \mathrm{C}$ no interior da leira. No estágio mesofílico, bactérias e fungos mesofílicos são responsáveis pela degradação da matéria orgânica e posteriormente, quando as temperaturas sobem acima de $40^{\circ} \mathrm{C}$, a diversidade microbiana diminui e as bactérias e fungos termofílicos produzem enzimas que degradam os substratos presentes no composto (Ryckeboer et al., 2003). Finalizada a fase termofílica, as temperaturas reduzem. Fatores como o clima da região, a composição do material a ser compostado, granulometria, dimensões da leira, disponibilidade de oxigênio, teor de umidade, também influenciam a temperatura no interior da leira (Massukado, 2008).
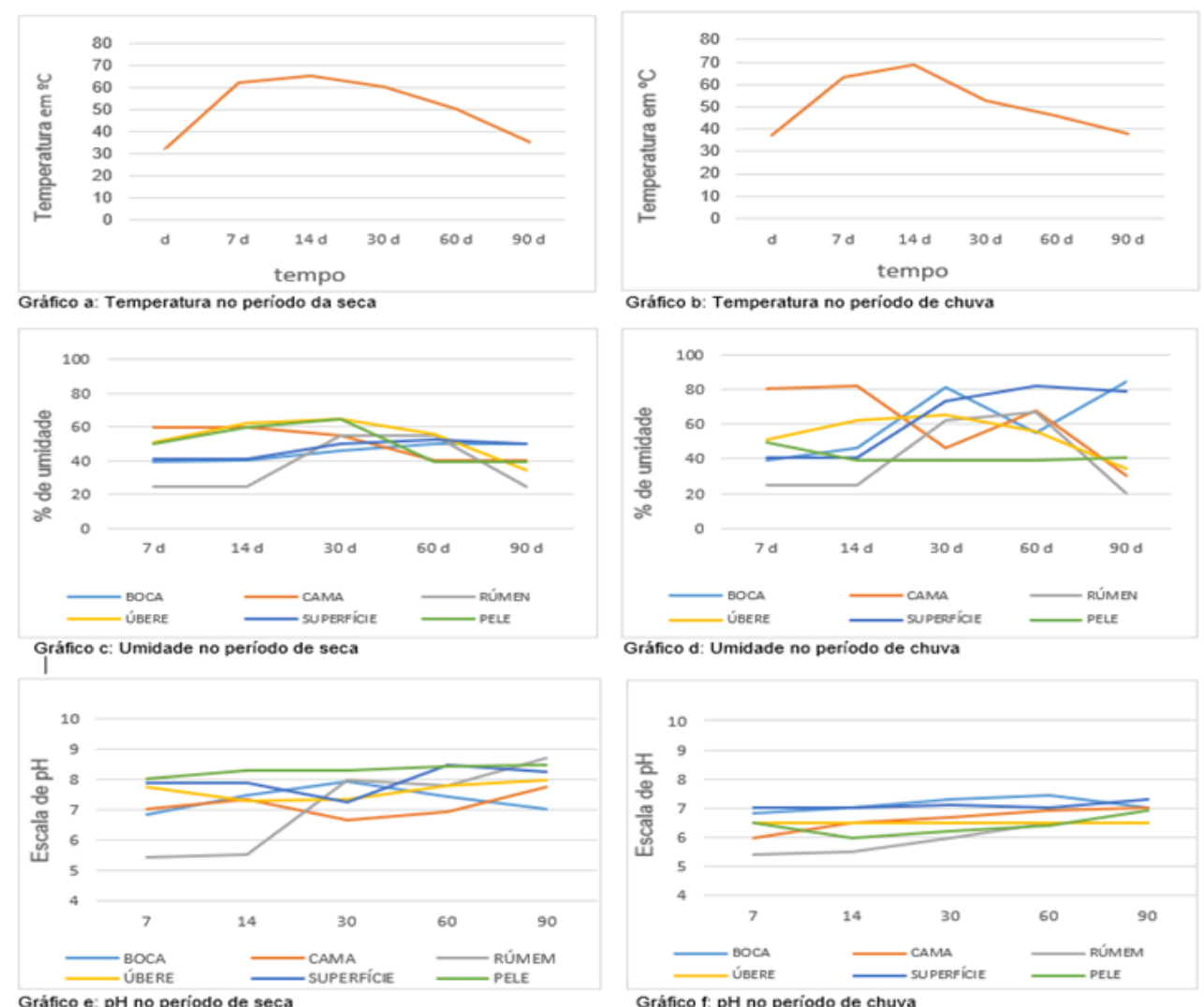

Gáfico c: Umidade no período de seca

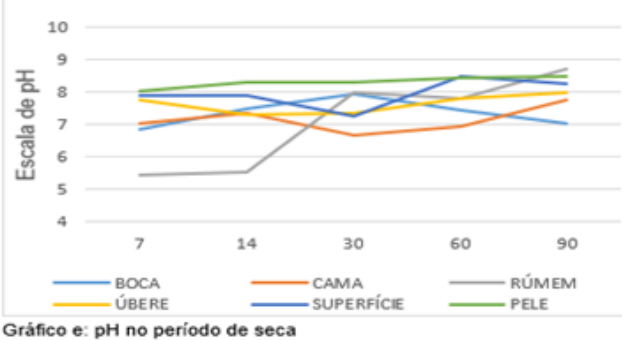

Gráfico f: $\mathrm{pH}$ no periodo de chuva

Figura 5. Parâmetros físico-químicos monitorados no período de compostagem; (A) Registro de temperatura dentro da leira de compostagem na estação seca; (B) Registro de temperatura dentro da leira de compostagem na estação seca; (C) Variação de umidade no interior da compostagem na estação seca; (D) Variação de umidade no interior da compostagem na estação chuvosa; (E) Variação de pH no interior da compostagem na estação seca; $(\mathbf{F})$ Variação de pH no interior da compostagem na estação chuvosa.

A umidade da leira na estação chuvosa foi mais alta, atingindo $80 \%$ (d), enquanto na estação seca variou entre 40 e $60 \%$ (c). Esses resultados estão relacionados com o clima da região onde foi realizado o experimento, que possui uma estação chuvosa com muita precipitação e uma estação seca com pouca precipitação, isto bastante pronunciado e característico. Segundo Valente et al. (2009) elevados teores de umidade devem ser evitados durante a compostagem. O excesso de umidade dificulta a oxigenação da leira propiciando condições anaeróbias e formação de "chorume", caracterizando a lixiviação de nutrientes da massa a ser compostada. Apesar da umidade alta no período de chuva, não foi verificada presença de chorume, mau cheiro ou moscas nas leiras de compostagem. A umidade presente na compostagem era oriunda do fluido corporal da carcaça bovina misturada ao material vegetal e vapor condensado devido as altas temperaturas alcançadas durante o processo.

$\mathrm{O}$ valor do $\mathrm{pH}$ no meio da compostagem é extremamente relevante, pois influenciam o perfil da população microbiana durante a compostagem. Awasthi et al. (2019) relataram que a fermentação com $\mathrm{pH}$ mais alto ou básico poderia reduzir significativamente a abundância de microrganismos, ocorrido devido a inibição da reprodução das bactérias, retardando o processo de compostagem. Os valores encontrados em ambas as épocas tendem à neutralidade conforme mostrado na figura 5 (e) e (f), o que favorece as reações metabólicas dos microrganismos decompositores. 
A degradação do material durante a compostagem é dependente da atividade microbiana presente em cada fase. Alguns autores relatam, no entanto, que valores superiores ou inferiores aqueles (na faixa de 4,5-9,5) não limitam definitivamente o processo, uma vez que os microrganismos conseguem regular o meio via degradação de compostos, produzindo subprodutos ácidos ou básicos, conforme a necessidade (Pereira, 2007) Já para valores altos de pH, acima de 9,5, há no processo a deficiência de micronutrientes e fósforo, além de perdas de nitrogênio por volatilização, devido à transformação do íon amônio $\left(\mathrm{NH}_{4}^{+}\right)$em amônia $\left(\mathrm{NH}_{3}\right)$ (Massukado, 2008). Ao final do processo espera-se que o composto apresente $\mathrm{pH}$ entre 6 e 7, intervalo este em que os macros e micronutrientes estão mais disponíveis para a aplicação do composto no solo (Gardoni \& Azevedo, 2019; Magalhães et al., 2018).

\section{Efeito da compostagem sobre os microrganismos}

A compostagem de carcaças precisa de medidas de segurança para reduzir a possível propagação de contaminações por patogenos. A temperatura influencia diretamente nas mudanças na comunidade microbiana durante o processo de compostagem (Asses et al., 2019).

Nos envelopes analisados na estação seca e chuvosa, os resultados mostram que houve redução da presença de microrganismos nas coletas com sete dias e 14 dias de compostagem. Com 30 dias, amostras dos envelopes do úbere, rúmen, boca e pele apresentam presença dos microrganismos Escheriachia coli, Staphilococcus aureus e Listeria monocytogenes na estação seca. Na estação chuvosa, amostras dos envelopes do úbere e rúmen apresentam presença dos microrganismos Escheriachia coli, Bacillus cereus e Listeria monocytogenes. Após 60 dias, na estação seca os resultados foram negativos para os microrganismos analisados. Na estação chuvosa, com 60 dias, havia ainda presença de Staphilococcus aureus e Escheriachia coli. Aos 90 dias de compostagem. Os resultados das amostras dos envelopes foram negativos para todas as bactérias analisadas, conforme apresentado na figura $\underline{6}(\underline{a})$ e ( $\underline{b})$. Segundo Xu et al. (2014), temperaturas altas alcançadas nas leiras de compostagem por períodos longos são geralmente eficazes na decomposição de carcaças. ainda mostraram que mais de $90 \%$ dos patogenos são eliminados nos primeiros sete dias da fase termofílica da compostagem.

As amostras do material vegetal do interior das esferas analisadas, nas estações chuvosa e seca, apresentam uma redução da presença de microrganismos nas coletas com 14 dias de compostagem. Com 30 dias, amostras das esferas do úbere e rúmen apresentam presença dos microrganismos Escheriachia coli, Bacillus cereus e Listeria monocytogenes nas estações chuvosa e seca. Após 60 dias os resultados foram negativos para os microrganismos analisados nas estações seca e chuvosa, conforme apresentado na Figura 6 (c) e (d). Esses resultados mostram que as bactérias inoculadas, que estavam dentro dos envelopes, foram eliminadas e não foram transferidas, para o material vegetal que compunha o "recheio" das esferas, ou foram eliminadas pelo processo de compostagem.

Conforme mostrado na figura 6 (e) e (f), as amostras do material vegetal do entorno das esferas, na estação chuvosa e estação seca, apresentam uma redução da presença de microrganismos nas coletas com 14 dias de compostagem. Com 30 dias de compostagem Escherichia coli e Salmonella typhimurium ainda estavam presentes em todas as amostras de material vegetal do entorno das esferas, Listeria monocytogenes e Pseudomonas aeruginosa estavam presentes nas amostras em torno do rúmen e boca. Os microrganismos Enterococcus faecalis, Bacillus cereus, e Strepetococcus uberis não foram encontrados a partir de 30 dias. Após 60 dias, na estação seca os resultados foram os mesmos encontrados com 30 dias. Na estação chuvosa, com 60 dias, os microrganismos Escheriachia coli, Salmonella typhimurium e Listeria monocytogenes foram encontradas nas amostras de material vegetal do entorno das esferas do rúmen, boca, pele e parte superior. E com 90 dias, na estação seca foi encontrado Escherichia coli em todas as amostras e na estação chuvosa, foram encontradas Escheriachia coli e Salmonella typhimurium nas amostras de material vegetal do entorno das esferas do rúmen. Esses resultados indicam que não houve influência dos microrganismos inoculados, isto é, estes microrganismos encontrados são originários do ambiente externo. Esses pontos são sítios naturalmente contaminados, ricos em nutrientes que favorecem o desenvolvimento de microrganismos. Ainda pode se inferir que pelo tipo de microrganismo encontrado este prevaleceu por se ubíquo e por suportar mais variações de temperatura e temperaturas altas (Matsunaga et al., 2019). 
Os microrganismos Streptococcus uberis e Staphilococcus aureus são caracteristicamente patogênicos e relacionados a doenças dos animais. As vacas utilizadas neste experimento eram sadias, o que justifica a ausência destes microrganismos nas amostras de material vegetal do entorno das esferas.
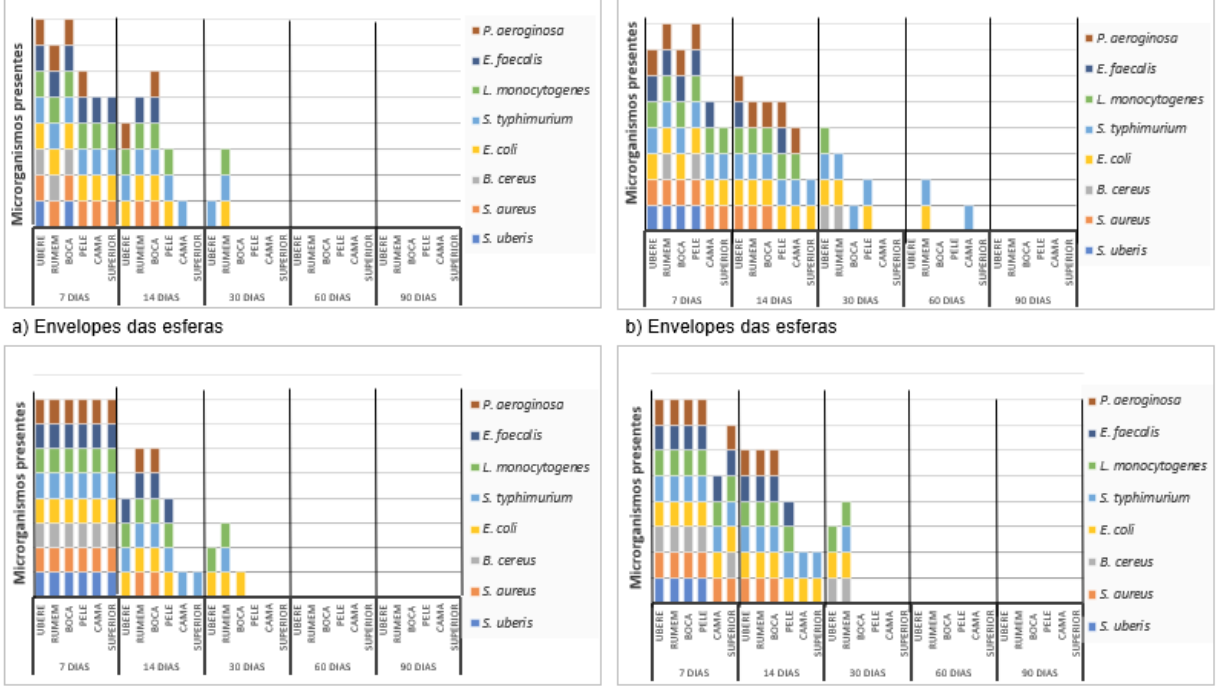

b) Envelopes das esferas

c) Interior das esfera
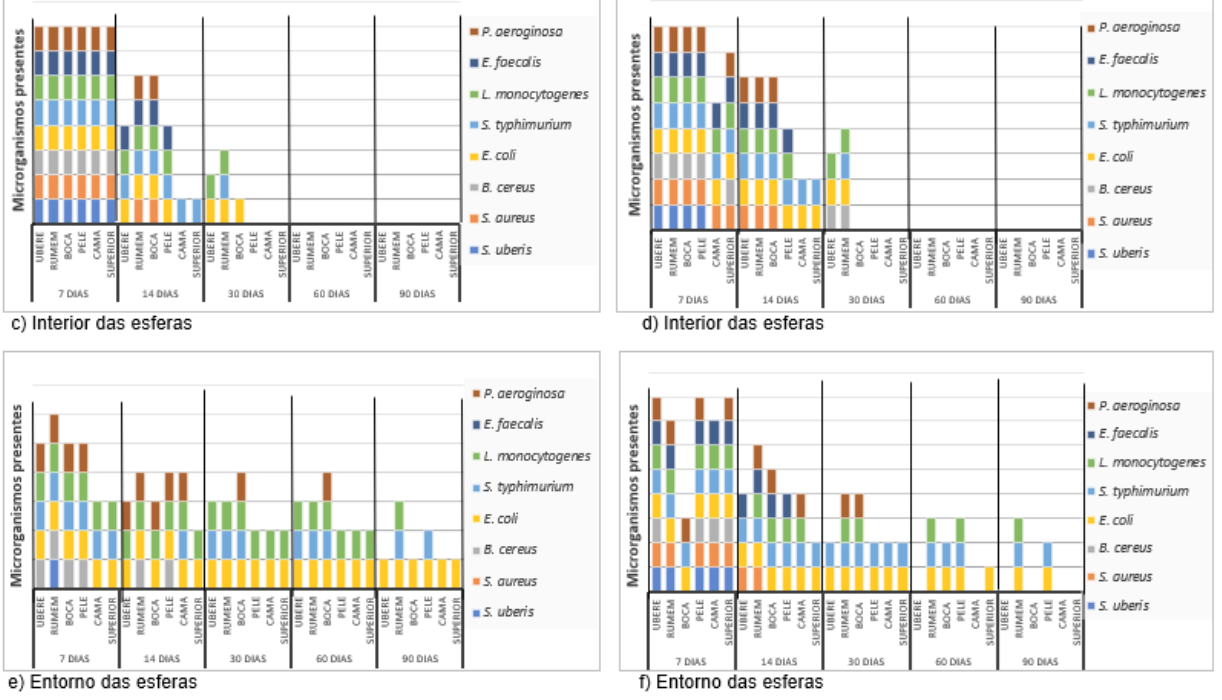

Figura 6. (A) Análise qualitativa (presença/ausência) de microrganismos nas amostras dos envelopes das esferas coletas na compostagem na estação seca; (B) Análise qualitativa (presença/ausência) de microrganismos nas amostras dos envelopes das esferas coletas na compostagem na estação chuvosa; (C) Análise qualitativa (presença/ausência) de microrganismos nas amostras do material vegetal do interior das esferas coletada da compostagem na estação seca; (D) Análise qualitativa (presença/ausência) de microrganismos nas amostras do material vegetal do interior das esferas coletada da compostagem na estação chuvosa; (E) Análise qualitativa (presença/ausência) de microrganismos nas amostras do material vegetal do entorno das esferas coletada da compostagem na estação seca; (F) Análise qualitativa (presença/ausência) de microrganismos do entorno das esferas coletada da compostagem na estação chuvosa.

Os ruminantes são considerados reservatórios de várias bactérias potencialmente patogênicas, como Escherichia coli, Salmonella spp. e Listeria monocytogenes (Munir \& Xagoraraki, 2011; Resende et al., 2014). Entretanto os resultados das amostras de material vegetal demonstraram a presença destes microrganismos nas amostras analisadas, em desdobramento e continuidade do estudo análise de biologia molecular deverá ser realizada para verificar se os microrganismos inoculados nas esferas são os mesmos encontrados no exterior das esferas, como Salmonella typhimurium, Listeria monocytogenes e Escheriachia coli, que permaneceram no produto final da compostagem. Escheriachia coli é uma bactéria naturalmente presente em todos os animais de sangue quente, incluindo humanos e estudos realizados por Ishii \& Sadowsky (2008) mostraram que esta bactéria sobrevive em diferentes habitats como água, sedimentos e solo. E foi encontrada em todas as amostras do entorno na estação seca e nas amostras do entorno do rúmen e pele na estação chuvosa. A presença de Escheriachia coli na estação seca pode ter sido influenciada pelas temperaturas mais baixas deste período. E a medida de temperatura foi realizada em um ponto interno da leira, podendo algumas partes não ter alcançado temperatura suficiente para eliminação deste microrganismo que é termofílico. Shepherd Junior et al. (2010) determinaram que variações de temperatura nas bordas das leiras de compostagem devido a variações de temperatura ambientes provavelmente explica a persistência de coliformes e microrganismos patogênicos na superfície do composto. 
Salmonella typhimurium manteve-se presente nas amostras do entorno do rúmen e pele (figuras 6 (e) e (f)). Este micorganismo é uma bactéria patogêncica e pode sobreviver no solo por muito tempo. Resultados diferentes deste encontrado neste experimento, podem ser vistos nos estudos realizados por Awasthi et al. (2019) que mostraram que Salmonella foi removida completamente após 30 dias de em compostagem de resíduos de matadouro, e estudos de Pandey et al. (2016) mostraram que Salmonella diminuiu de forma significativa em 5 a 34 dias de compostagem de resíduos de alimentos.

Listeria monocytogenes é um patógeno oportunista e onipresente na natureza e adapta-se em situações de estresses como variação de temperatura (Piveteau et al., 2011). Os achados deste trabalho indicam a persistencia deste microrganismo em amostras do entorno das esferas da boca e do rúmen, do mesmo modo que para os outros microrganismos que persistiram esta pode ter sua origem de fontes ambientais, como solo ou material vegetal utilizado na compostagem. Como referido para os outros microrganismos remanescentes, vamos dar continuidade ao estudo buscando novos recursos financeiros para condução de análise de biologia molecular para verificar se os microrganismos inoculados nas esferas são os mesmos encontrados no exterior das esferas.

Awasthi et al. (2019) concluíram que temperaturas entre $55-60^{\circ} \mathrm{C}$ por 3 a 4 dias são eficazes para inativar microrganismos patogênicos, desde que o aquecimento seja contínuo e uniforme em toda a leira da compostagem. (Gurtler et al., 2014) relatam que muitas pesquisas de preparações de composto foram conduzidas para determinar se as condições ocorridas durante a compostagem foram suficientes para inativar patógenos ou reduzir as populações de bactérias indicadoras a níveis que minimizariam os riscos associados ao composto.

A presença de patógenos em amostras retiradas do entorno das esferas, e ausência dos patógenos inoculados dentro das esferas após 90 dias de compostagem, indica que microrganismos naturais desses ambientes são mais resistentes e termotolerantes. Ainda a inativação do que foi inoculado, ou seja, do que estava dentro do envelope é a resposta que suporta a afirmação de que a compostagem elimina microrganismos patogênicos que possam estar presentes na carcaça de animais mortos.

\section{Conclusão}

A compostagem é uma alternativa prática e simples para destinação de carcaças de grandes animais. Além de ser de baixo custo, dispensando o manejo durante o processo.

Os resultados deste estudo mostraram que o processo é eficiente e seguro, desde que manejado adequadamente e que os parâmetros de tempo e teperatura alta seja alcaçados para eliminação das bactérias patogências. A manutenção da umidade em combinação com altas temperaturas foram os fatores decisivos na eliminação dos microrganismos inoculados.

Este trabalho reforça que a montagem da leira e o manejo adequado da compostagem inlfuenciam a degradação da carcaça e inativação de bactérias patogêncas.

\section{Referências bibliográficas}

ANVISA Agência Nacional de Vigilância Sanitária. (2013). Microbiologia Clínica para o Controle de Infecção Relacionada à Assistência à Saúde. Módulo 6: Detecção e identificação de bactérias de importância médica /Agência Nacional de Vigilância Sanitária.

ANUALPEC. (2019). Anuário da Pecuária Brasileira (20th ed. Vol. 1). São Paulo, São Paulo, Brasil: Instituto FNP.

Asses, N., Farhat, W., Hamdi, M. \& Bouallagui, H. (2019). Large scale composting of poultry slaughterhouse processing waste: Microbial removal and agricultural biofertilizer application. Process Safety and Environmental Protection, 124128-136.

Awasthi, M. K., Chen, H., Duan, Y., Liu, T., Awasthi, S. K., Wang, Q., . . Z Zhang, Z. (2019). An assessment of the persistence of pathogenic bacteria removal in chicken manure compost employing clay as additive via meta-genomic analysis. Journal of Hazardous Materials, 366184-191.

Brinton, W. F., Bonhotal, J. \& Fiesinger, T. (2012). Compost sampling for nutrient and quality parameters: variability of sampler, timing and pile depth. Compost Science \& Utilization, 20(3):141149. 
Cooper, M., Zanon, A. R., Reia, M. Y. \& Morato, R. W. (2010). Compostagem e reaproveitamento de resíduos orgânicos agroindustriais: teórico e prático. Piracicaba, São Paulo, Brasil: ESALQ/USP.

Diniz Filho, E. T., Mesquita, L. d., Oliveira, A. d., Nunes, C. G. F. \& Lira, J. F. B. (2007). A prática da compostagem no manejo sustentável de solos. Revista Verde de Agroecologia e Desenvolvimento Sustentável, 2(2):27-36.

Ferraz, J. B. S. \& Felício, P. E. (2010). Production systems - An example from Brazil. Meat Science, 84(2):238-243. doi: http://dx.doi.org/10.1016/j.meatsci.2009.06.006.

Gardoni, R. A. P. \& Azevedo, M. d. A. (2019). Estudo da biodegradação de carcaças de aves por meio do processo de compostagem em biodigestores fechados descontínuos. Engenharia Sanitaria e Ambiental, 24(3):425-429.

Gurtler, J. B., Boateng, A. A., Han, Y. \& Douds Jr, D. D. (2014). Inactivation of E. coli O157: H7 in cultivable soil by fast and slow pyrolysis-generated biochar. Foodborne pathogens and disease, 11(3):215-223.

Ishii, S. \& Sadowsky, M. J. (2008). Escherichia coli in the environment: implications for water quality and human health. Microbes and Environments, 23(2):101-108.

Kalbasi, A., Mukhtar, S., Hawkins, S. E. \& Auvermann, B. W. (2005). Carcass composting for management of farm mortalities: a review. Compost science \& utilization, 13(3):180-193.

Kiehl, E. J. (2004). Manual de compostagem: maturação e qualidade do composto (Vol. 1). Piracicaba: Degaspari.

Köppen, W. \& Geiger, R. (1928). Klimate der Erde. Gotha: Verlag Justus Perthes. Wall-map $150 \mathrm{~cm} \times 200 \mathrm{~cm}$.

Krabbe, E. L. (2017). Destino de carcaça de animais mortos. Paper presented at the Embrapa Suínos e Aves-Artigo em anais de congresso.

Magalhães, A. C. M., Blum, J., Lopes, F. B. \& Tornquist, C. G. (2018). Production Components of the cowpea under different doses of organic fertiliser. Journal of Experimental Agriculture International, 26(5):1-9.

Massukado, L. M. (2008). Desenvolvimento do processo de compostagem em unidade descentralizada e proposta de software livre para o gerenciamento municipal dos resíduos sólidos domiciliares. Universidade de São Paulo, São Paulo, Brasil.

Matsunaga, W. K., Rodrigues, H. J. B. \& Rodrigues, P. G. (2019). Atributos microbiológicos de solo, relacionados às atividades da microfauna em solo na floresta Amazônica. Anuário do Instituto de Geociências, 41(3):630-638.

Miller, P. R. M. \& Inácio, C. T. (2009). Compostagem: ciência e prática para a gestão de resíduos orgânicos: Embrapa Solos.

Munir, M. \& Xagoraraki, I. (2011). Levels of antibiotic resistance genes in manure, biosolids, and fertilized soil. Journal of Environmental Quality, 40(1):248-255.

Pandey, P. K., Cao, W. \& Vaddella, S. V. (2016). A new closed loop heating system for composting of green and food wastes. Journal Of Cleaner Production, v. 133, p.1252-1259.

Paula, V. R. de; Otenio, M. H.; Silva, M. R.; Ribeiro, J. B.; Mores, N.; Tapparo, D. G.. Destinação de carcaças de bovinos em propriedades rurais. (2017). In: Simpósio internacional sobre gerenciamento de resíduos agropecuários e agroindustriais, 5, 2017, Foz do Iguaçu, Anais... Concórdia: Sbera: Embrapa Suínos e Aves. SIGERA. p. 503-506.

Pereira, J. T. (2007). Manual de compostagem: processo de baixo custo. Viçosa, Minas Gerais, Brasil: Universidade Federal de Viçosa.

Piveteau, P., Depret, G., Pivato, B., Garmyn, D. \& Hartmann, A. (2011). Changes in gene expression during adaptation of Listeria monocytogenes to the soil environment. PloS One, 6(9):e24881.

Prado, I. N. (2010). Produção de bovinos de corte e qualidade da carne (Vol. 1). Maringá, Paraná, Brasil: Eduem.

Otenio, M. H.; Cunha, C. M. da; Rocha, B. B. (2010). Compostagem de carcaças de grandes animais. 2010.4f. Comunicado Técnico EMBRAPA, nº 61 . 
Resende, J. A., Silva, V. L., Oliveira, T. L. R., Oliveira Fortunato, S., Carneiro, J. C., Otenio, M. H. \& Diniz, C. G. (2014). Prevalence and persistence of potentially pathogenic and antibiotic resistant bacteria during anaerobic digestion treatment of cattle manure. Bioresource Technology, 153284291.

Rocha, C. P. (2012). Análise da eficiência sanitária no tratamento de carcaças avícolas através da compostagem no município de São Sebastião do Oeste-MG. Conexão Ciência, 7(2):14-27.

Ryckeboer, J., Mergaert, J., Vaes, K., Klammer, S., De Clercq, D., Coosemans, J., . . Swings, J. (2003). A survey of bacteria and fungi occurring during composting and self-heating processes. Annals of Microbiology, 53(4):349-410.

Sanes, F. S. M., Strassburger, A. S., Araújo, F. B. \& Medeiros, C. A. B. (2015). Compostagem e fermentação de resíduos de pescado para produção de fertilizantes orgânico. Semina: Ciências Agrárias, 36(3):1241-1251.

Santos Nascimento, M., Pereira, S. J. B., Santos, R. F. \& Vieira, A. M. (2018). Avaliação e caracterização do processo de compostagem de resíduos de peixes. PUBVET, 12(11):1-7.

Shepherd Junior, M. W., Liang, P., Jiang, X., Doyle, M. P. \& Erickson, M. C. (2010). Microbiological analysis of composts produced on South Carolina poultry farms. Journal of Applied Microbiology, 108(6):2067-2076.

Valente, B. S., Xavier, E. G., Morselli, T. B. G. A., Jahnke, D. S., Brum Júnior, B. S., Cabrera, B. R., . . Lopes, D. C. N. (2009). Fatores que afetam o desenvolvimento da compostagem de resíduos orgânicos. Archivos de Zootecnia, 58(1):59-85.

Xu, S., Reuter, T., Stanford, K., Larney, F. J. \& McAllister, T. A. (2014). Composting as a method for carrion disposal in livestock production.

Recebido: 16 de outubro, 2019.

Aprovado: 22 de novembro, 2019.

Publicado: 10 de março, 2020.

Licenciamento: Este artigo é publicado na modalidade Acesso Aberto sob a licença Creative Commons Atribuição 4.0 (CC-BY 4.0), a qual permite uso irrestrito, distribuição, reprodução em qualquer meio, desde que o autor e a fonte sejam devidamente creditados. 